\title{
Predicting onset and success of breeding in little penguins Eudyptula minor from ocean temperatures
}

\author{
J. M. Cullen ${ }^{\ddagger}$, L. E. Chambers ${ }^{1, *}$, P. C. Coutin ${ }^{2}$, P. Dann ${ }^{3}$ \\ ${ }^{1}$ Centre for Australian Weather and Climate Research-Bureau of Meteorology, GPO Box 1289, Melbourne, Victoria 3001, \\ Australia \\ ${ }^{2}$ Marine and Freshwater Fisheries Research Institute, Department of Primary Industries, PO Box 114, Queenscliff, \\ Victoria 3225, Australia \\ ${ }^{3}$ Research Department, Phillip Island Nature Park, PO Box 97, Cowes, Victoria 3922, Australia
}

\begin{abstract}
As is the case for many seabirds, we found that the timing and breeding success of little penguins Eudyptula minor on Phillip Island, southeastern Australia, was associated with sea surface temperature (SST) variation. Using 31 yr of data (1968 to 1998), we examined the correlations between breeding variables and regional SST at different times of the year. The next 9 yr of data (1999 to 2007) were used to test the performance of our statistical predictive models. Egg-laying date, chick mass and the number of chicks fledged per pair were correlated with SST in the first 3 mo of the year prior to breeding, in slightly different ways. SST provided more accurate predictions of mean laying date $(53 \%$ variance) than of chicks produced per pair $(22 \%)$ or mean chick mass at fledging $(16 \%)$. This model predicted an early egg-laying date, higher average chick mass at fledging and a higher number of chicks produced per breeding pair when SSTs in Bass Strait are warmer than average in March. The models presented predict that an increase in SST is likely to lead to a reversal of the trend towards later breeding and suggest improved growth of the colony of little penguins on Phillip Island, at least in the immediate future.
\end{abstract}

KEY WORDS: Little penguins $\cdot$ Reproduction $\cdot$ Climate change $\cdot$ Modelling $\cdot$ Southern Australia Phillip Island

\section{INTRODUCTION}

Oceanographic variation is known to affect seabirds throughout the world, particularly where upwelling and boundary currents have a major influence on local sea surface temperature (SST) and marine productivity (Boersma 1978, 1987, Ainley et al. 1988, Crawford \& Jahncke 1999, Velarde et al. 2004, Congdon et al. 2007). For example, warm-water events in the Pacific have been linked to increased mortality and reduced breeding success of seabirds in the USA (Hodder \& Graybill 1985), Peru (Ainley et al. 1988, Crawford \& Jahncke 1999, Glantz 2001), southern Africa (La Cock 1986, Crawford \& Jahncke 1999) and throughout the Pacific basin (Ainley et al. 1988, Glantz 2001). In the Southern Ocean, rising SST has also been linked to population declines of the rockhopper penguin Eudyptes chrysocome at Campbell Island (Cunningham \& Moors 1994) and the emperor penguin Aptenodytes forsteri in the Antarctic (Barbraund \& Weimerskirch 2001).

Variable oceanographic conditions influence both prey density and seabird foraging (Ainley \& Boekelheide 1990, Robinson et al. 2005, Congdon et al. 2007). For example, cold surface waters in the northwest Atlantic have been associated with movement patterns of migratory pelagic fish (Montevecchi \& Myers 1996) and breeding failures of surface-feeding seabirds (Re 
gehr \& Montevecchi 1997). Peak spawning times of capelin Mallotus villosus were also later and fish were smaller during a period of below-normal sea temperatures in this region (Carscadden et al. 1997).

Ocean temperatures may also influence the timing and success of breeding of seabirds (Ainley \& Boekelheide 1990, Guinet et al. 1998, Inchausti et al. 2003, Irons et al. 2008). Inchausti et al. (2003) found that the breeding success of 4 seabird species foraging in Antarctic waters south of the Polar Front was negatively affected by warm SST, mainly in winter and spring.

On the southern coast of Australia, at Phillip Island, there is an internationally significant ecotourism attraction that features a colony of little penguins Eudyptula minor. Understanding the factors that affect their breeding success and being able to predict population trends are particularly important for providing scientific advice on management responses to climate change forecasts. Little penguins show marked annual differences in the timing and success of breeding (Reilly \& Cullen 1981, Dann \& Cullen 1990, Dann et al. 2000, Kemp \& Dann 2001). Much of this variation is probably related to the onset of breeding because there is comparatively little variation in the conclusion of the breeding season due to the onset of moult (Reilly \& Cullen 1981). The timing of breeding has important implications, as early breeding is generally more successful (Reilly \& Cullen 1981).

Penguin breeding may be affected by changes in marine productivity associated with SST and driven by oceanographic processes (Middleton \& Cirano 2002). However, for the little penguins at Phillip Island, the relationship between their marine environment and the timing and success of breeding is difficult to determine. SST around southeastern Australia is influenced by waters from 4 regions (Gibbs 1992). Bass Strait water around Phillip Island originates mostly from the west, flowing east across South Australia as low nutrient subtropical water from the Great Australian Bight. From the north, the East Australian Current (EAC) flows south, bringing eddies of warm nutrient-poor tropical water of the Pacific Ocean. There is mixed subtropical Central Tasman water in the east. In the south and in deep water beyond the continental shelf, cold, nutrient-rich sub-Antarctic water originates from below the Subtropical Convergence Zone and the eastward flowing Antarctic Circumpolar Current in higher latitudes. The interaction of these 4 water masses, which is influenced by the seasonal wind patterns, determines the nature of the marine environment of the little penguins and the productivity of marine ecosystems in southeastern Australia.

Mickelson et al. (1992) found that 29 and $47 \%$ of the interannual variability in the body mass and breeding success of the little penguin on Phillip Island was attributed, by correlation analysis, to monthly and interannual decreases in the east-west SST gradient for 2 areas in Bass Strait between the moulting and breeding periods. The mass of adult birds increased 4 mo after the decrease in SST as west winds brought cooler waters with slightly higher nutrients into Bass Strait. The authors concluded that early egg laying in September and October was associated with a decrease in the SST in July and August.

Based on that, J. M. Cullen (unpubl. data) produced statistical models to predict the mean laying date using a long-term dataset of penguin breeding parameters at Phillip Island and SST data during the 1990s. We have continued his work using a more extensive time series of data to explore the relationships between the timing of breeding, the numbers of chicks produced per pair and the mass of chicks and SST at various times prior to breeding. These relationships may help to reveal the ecological basis underlying a substantial part of the variability in breeding and could be used for predicting annual penguin productivity.

\section{MATERIALS AND METHODS}

Timing and success of little penguin breeding. Field work was conducted on the Summerland Peninsula, Phillip Island, Victoria, Australia (38 $\left.30^{\prime} \mathrm{S}, 145^{\circ} 10^{\prime} \mathrm{E}\right)$ from 1968 to 2007 . Approximately 26000 little penguins are estimated to nest at this site (J. M. Cullen unpubl. data). Penguins nest in burrows in sandy soil and among bushy vegetation on slopes and flat ground up to $50 \mathrm{~m}$ above sea level; about half the birds included in this study nested in artificial burrows (nest boxes). The number and location of study sites visited and the frequency of visits to the burrows in these study sites have varied over the years. The frequency of visits to burrows in the initial study area was weekly from 1968 to 1970 and monthly from 1971 to 1984 . From 1985 to 2004 it was every 2 wk during the breeding season and monthly outside the breeding season (Reilly \& Cullen 1981, Dann \& Cullen 1990, Dann et al. 1995). An additional 6 study sites were added between 1981 and 1984, and visited monthly until 1999, then at 2 wk intervals during breeding and infrequently at other times. On each visit, the band number(s) of the adult(s) present in the burrow, and the numbers of eggs and/or chicks were recorded. Sexes of adults were determined from bill lengths, distended cloacae in females at the time of egg laying, attendance patterns around the time of egg laying, and/or repeated cohabitation with other sexed birds (Dann \& Cullen 1990, Arnould et al. 2004).

We compared 3 annual breeding parameters with monthly patterns of SST: the mean laying date of first 
clutches (MLD), the mean number of chicks fledged per pair of birds that laid eggs (CPP), and the mean mass of chicks (CMass) at the age of about 6 to $8 \mathrm{wk}$ when they were marked prior to fledging. Because the breeding season of the penguins overlaps the calendar year, all the data are for the period starting in March and ending in February of the following year, and are recorded as the year in which the season started. Laying dates, if not observed, were inferred retrospectively from hatching dates or the age of young chicks. For mean laying date, the integer represents the month and the decimal part represents which day of the month (e.g. 15 September is 9.5, shown in Fig. 4 with associated error bars).

Chicks were banded on the flipper prior to fledging and most breeding adults were banded from 1968 until 2000. Since 2000, most birds have been marked with implanted transponders instead of flipper bands. Chicks were deemed to have fledged if they disappeared after attaining their adult plumage and there were no indications of starvation or predation.

SST. SST data of $1^{\circ} \times 1^{\circ}$ spatial resolution were extracted for the period 1968 to the end of 1981 from the UK Meteorological Office Ice and Sea Surface Temperature data set (GISST, version 1.1; Parker et al. 1995). This data set was extended to June 2008 using data from the National Oceanographic and Atmospheric Administration (ftp://ftp.emc.ncep.noaa.gov/cmb/sst/ oimonth_v2/) and represents mean SST values per $1^{\circ}$ degree grid square per month, covering the whole globe (Reynolds \& Smith 1994). These monthly values, 'optimum interpolation' (OI) fields, are derived by a linear interpolation of the weekly OI fields to daily fields, which are then averaged for the month. Before that analysis is computed, the satellite data were adjusted for bias due to water evaporation and checked against ground truth data when available. A description of the OI analysis can be found in Reynolds \& Smith (1994). SST covering the region from $35^{\circ}$ to $45^{\circ} \mathrm{S}$ and $138^{\circ}$ to $152^{\circ} \mathrm{E}$ were used in the analysis because this area is influenced by the 4 water masses identified by Gibbs (1992) and represents 'local' SST.

Data analysis. Data collected from 1968 to 1998 were used to develop relationships between SSTs and penguin breeding variables. Data collected from 1999 to 2007 were used to test the predictive capacity of these relationships.

Correlations: For each of the SST grid squares that included more than $50 \%$ sea in area, and for each month of the year, the correlation coefficient was calculated between the value of each penguin variable for that year and the SST for the month in that year. The correlations were plotted for each degree square of sea (see Fig. 2) in contour form with shaded areas depicting the values statistically significant at the $5 \%$ level.
SST sub-region analysis: As the gridded SST data had very high spatial correlations ( $p \leq 0.001$ for all grid points), the average of SST over a subset of the entire region was considered for all further analyses. This SST box (situated between $38^{\circ}$ and $40^{\circ} \mathrm{S}$ and $143^{\circ}$ and $145^{\circ}$ E, Fig. 1) was selected, as water movement into Bass Strait prior to the breeding season is predominantly from the west (Gibbs 1992) and penguins from Phillips Island are known to forage within this area prior to the start of the breeding season (Collins et al. 1999). However, similar results would be obtained by taking any subset of the SST data, given the high spatial correlation in the SST. The median of the SST averages, over all months, within this box was $15.14^{\circ} \mathrm{C}$ (range 12.24 to $19.13^{\circ} \mathrm{C}$ ) and, for comparison, during March was $17.73^{\circ} \mathrm{C}$ (range 16.42 to $19.09^{\circ} \mathrm{C}$ ).

The monthly sub-regional averages were then used to obtain a correlation coefficient with each penguin breeding variable for each month.

Regression analysis: Using multiple linear regression, the mean monthly regionally averaged SST was used to determine the optimal model for predicting mean laying date, the mean number of chicks fledged per pair and the mean chick fledging mass. Examination of the model residuals indicated any 'unusual'

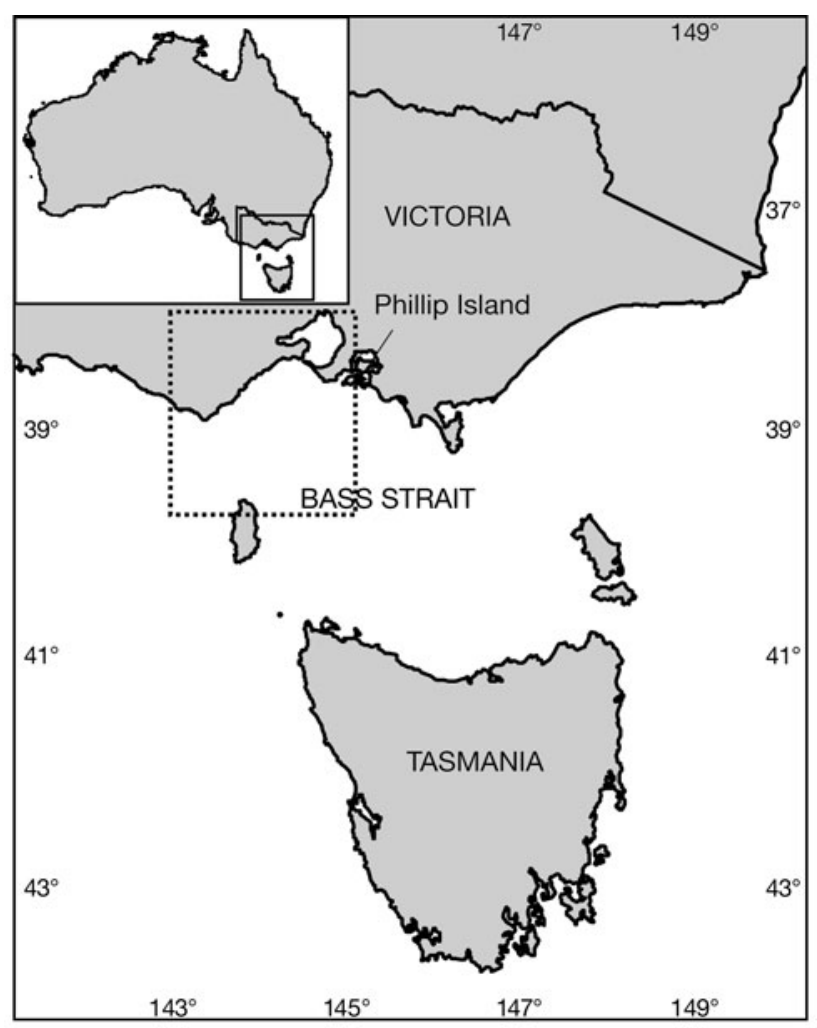

Fig. 1. Area of study showing the sea surface temperature sub-region used in the analysis (dotted line) 
years. The model selected was then used in forecast mode and predictions were made of the penguin variables for the years 1999 to 2007 . Comparisons between the model values and the observed values over this period give a more realistic indication of the expected model skill for future predictions. Statistically significant correlation was set at the $5 \%$ level.

\section{RESULTS}

\section{Correlations}

Correlations for each of the penguin variables were highest for the early months of the year, some time before breeding starts, with the strongest correlations generally occurring in March. The correlation coefficients between MLD and SST were generally stronger than those between SST and other variables.

For the MLD, negative correlations indicated that warm SST corresponded to earlier nesting. Correlations were highest in the region between Tasmania and the mainland (including western Bass Strait), and off the southeast coast of Australia (Fig. 2), and generally lowest in the southern part of the SST region considered. The strength of the correlations increased from February to March, before declining to a level of very few significant correlations by June.

For both CPP and CMass, correlations with SST early in the year prior to the start of breeding were positive, indicating that warmer water tended to correspond to increases in both CPP and the mean CMass at fledging. For both of these variables the highest correlations were with March SST (not shown).

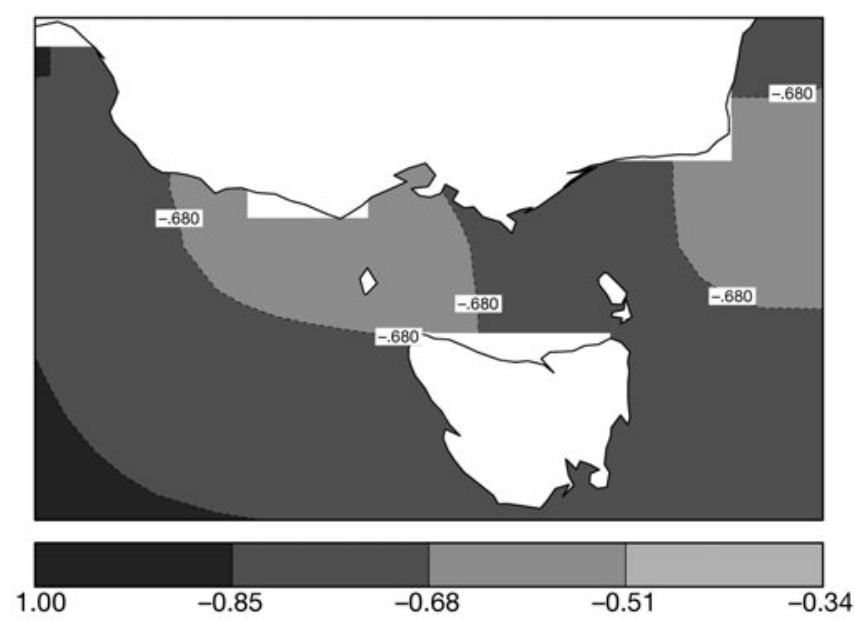

Fig. 2. Correlations between the gridded March sea surface temperature values and mean laying date of Eudyptula minor, 1968 to 1998. All correlations significant at the 5\% level are shaded
Table 1. Correlation coefficients between little penguin Eudyptula minor breeding variables (mean laying date, chicks per pair and chick mass) and regionally averaged monthly sea surface temperature, 1968 to 1998. Months beyond September were not considered for mean laying date as, in some years, the breeding season has already commenced. ${ }^{*}$ Correlations significant at the $5 \%$ level

\begin{tabular}{|lccc|}
\hline Month & $\begin{array}{c}\text { Mean laying } \\
\text { date }\end{array}$ & $\begin{array}{c}\text { Chicks per } \\
\text { pair }\end{array}$ & Chick mass \\
\hline January & -0.307 & 0.184 & 0.166 \\
February & $-0.498^{*}$ & 0.278 & 0.229 \\
March & $-0.736^{*}$ & $0.491^{*}$ & $0.433^{*}$ \\
April & $-0.495^{*}$ & $0.409^{*}$ & 0.342 \\
May & $-0.422^{*}$ & 0.348 & 0.279 \\
June & -0.200 & 0.245 & 0.138 \\
July & -0.082 & 0.210 & 0.083 \\
August & 0.068 & 0.317 & -0.016 \\
September & 0.134 & 0.040 & -0.106 \\
October & - & -0.055 & -0.059 \\
\hline
\end{tabular}

\section{SST subregion analysis}

Using monthly averaged SST values, correlation coefficients with the penguin breeding variables were calculated (Table 1). Consistent with the correlations with individual SST grid boxes, the relationship between area-averaged SST and penguin breeding variables was strongest in March, particularly for MLD. Warm water during March, and to a lesser extent February and April, corresponded to an early start to egg laying. CPP and CMass were also strongly correlated with SST in the Bass Strait region, with a peak in the relationship occurring during March and decaying more rapidly than for mean laying date.

The advantage of using SST averaged over a subregion rather than SST values for individual grid squares is that there is a reduction in the number of variables describing the region, yet the basic seasonality and characteristics of the data remain intact. This was particularly useful when predictions of the breeding variables were made (see next section). Over the period 1968 to 1998, no significant temporal trend was observed in the area-averaged SST.

\section{Regression analysis}

Multiple linear regression was used to relate monthly area-averaged SST values to the penguin breeding variables. The initial regression equation fitted was of the form

$$
Y_{i}=a+b_{1} X_{m 1 i}+b_{2} X_{m 2 i}+b_{3} X_{m 3 i}
$$

where $Y_{i}$ is the penguin variable in year $i, X_{m 1 i}$ is the mean monthly SST value in month $m 1$ for year $i, \ldots$, 
and $X_{m 3 i}$ is the mean monthly SST value in month $m 3$ for year $i$. Given that most of the higher correlations between the variables and SST occurred during the early part of the year, $m 1$ to $m 3$ were selected from the months January to May. Using SST information from these months also allows a useful lead time for monitoring purposes and for planning a management response to the predictions.

Assessments were then made of the relative contribution of each of the SST variables to the model fit and only those with significant contributions retained. This was achieved using best subset regression (Tabachnick \& Fidell 1996).

For MLD, the model that explained a high proportion of the variance (approximately 53\%, p $\leq 0.001$ ), without over-fitting parameters, was

$$
\mathrm{MLD}=23.9-0.77 X_{\mathrm{March}}
$$

This model indicates that, during March, waters from the west of Bass Strait appear to influence the timing of breeding in little penguins.

SST accounted for less of the overall variation in CPP than for that in the timing of breeding (approximately $22 \%$ compared to $53 \%$ ). For CPP, western Bass Strait water during March proved to be the best potential predictor. The regression model is given by

$$
\mathrm{CPP}=-4.95+0.33 X_{\mathrm{March}}
$$

CMass at fledging was the least well predicted by SST of all the penguin breeding variables (percentage variance explained by the model was approximately $16 \%)$. The best model incorporated ocean temperatures during March in the Bass Strait region using the following equation

$$
\text { CMass }=10.2+50.9 X_{\text {March }}
$$

Data from 1999 to 2007 were then used to test the regression models' ability to predict the observed penguin breeding variables (Fig. 3). The results are shown in Table 2. CIs for the predictions, as well as prediction intervals, are given. Prediction intervals are always wider than confidence intervals, as the latter are based on confidence in predicting the mean response, whereas the former are based on predicting a single response.

Despite a better fit to the 1968 to 1998 data, predictions of MLD from 1999 to 2007 were generally not as good as those for CPP and CMass, with only 6 of the MLD prediction intervals containing the observed value. However, the prediction intervals for CPP and CMass were quite wide and, in the case of CMass, generally covered over $93 \%$ of the range of the 1968 to 1998 data (compared to an average of $77 \%$ for MLD). Comparing across all 3 penguin variables, the most 'accurate' predictions were for 1999, 2000, 2004 and
2005 and the least 'accurate' for 2001, 2002, 2003 and 2006 (MLD and CMass predictions also performed poorly in 2007).

For MLD, there has also been a trend towards later breeding over time $\left(\sim 0.65 \mathrm{~d} \mathrm{yr}^{-1}, \mathrm{p}=0.021\right.$; Fig. 4).
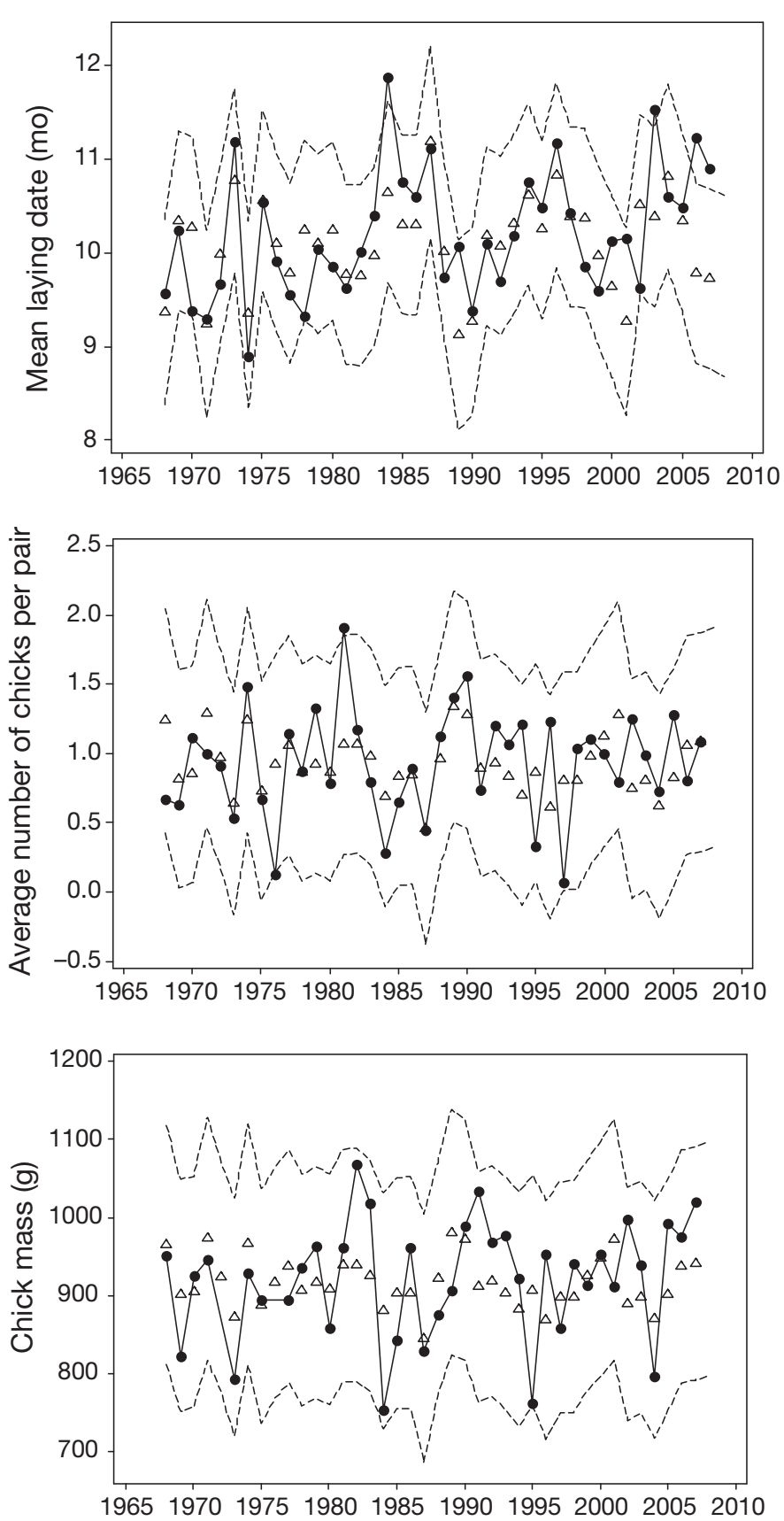

Fig. 3. Eudyptula minor. Observed $(\bullet)$ and modeled $(\Delta)$ breeding parameters, including prediction intervals (dashed lines). (a) Mean laying date; (b) chicks per pair; (c) chick mass at banding 
Table 2. Eudyptula minor. Predicted and observed mean laying dates (MLD), chicks fledged per pair (CPP) and mean mass of chicks at fledgling (CMass) from 1999 to 2007, using models developed from data from 1968 to 1998. SE of the predicted values are given, as well as $95 \%$ CIs for the predictions and $95 \%$ prediction intervals (95\% PI)

\begin{tabular}{|lrrrrr|}
\hline \multicolumn{7}{|c|}{ Observed Predicted SE } & $95 \%$ CI & $95 \%$ PI \\
\hline MLD & & & & & \\
1999 & 9.60 & 9.97 & 0.086 & $(9.80,10.15)$ & $(9.02,10.93)$ \\
2000 & 10.13 & 9.64 & 0.117 & $(9.40,9.87)$ & $(8.67,10.60)$ \\
2001 & 10.16 & 9.27 & 0.168 & $(8.92,9.61)$ & $(8.27,10.26)$ \\
2002 & 9.63 & 10.51 & 0.107 & $(10.30,10.73)$ & $(9.55,11.48)$ \\
2003 & 11.53 & 10.38 & 0.094 & $(10.19,10.57)$ & $(9.42,11.34)$ \\
2004 & 10.60 & 10.81 & 0.144 & $(10.52,11.11)$ & $(9.83,11.80)$ \\
2005 & 10.48 & 10.34 & 0.090 & $(10.15,10.52)$ & $(9.38,11.29)$ \\
2006 & 11.23 & 9.78 & 0.101 & $(9.57,9.99)$ & $(8.82,10.74)$ \\
2007 & 10.90 & 9.73 & 0.106 & $(9.41,9.88)$ & $(8.76,10.69)$ \\
CPP & & & & & \\
1999 & 1.11 & 0.98 & 0.071 & $(0.83,1.12)$ & $(0.19,1.76)$ \\
2000 & 1.00 & 1.12 & 0.096 & $(0.93,1.32)$ & $(0.33,1.92)$ \\
2001 & 0.80 & 1.28 & 0.138 & $(1.00,1.56)$ & $(0.46,2.10)$ \\
2002 & 1.25 & 0.75 & 0.088 & $(0.57,0.93)$ & $(0.00,1.54)$ \\
2003 & 0.99 & 0.81 & 0.077 & $(0.65,0.96)$ & $(0.02,1.59)$ \\
2004 & 0.73 & 0.62 & 0.119 & $(0.38,0.86)$ & $(0.00,1.43)$ \\
2005 & 1.28 & 0.82 & 0.074 & $(0.67,0.98)$ & $(0.04,1.61)$ \\
2006 & 0.81 & 1.06 & 0.083 & $(0.89,1.23)$ & $(0.27,1.85)$ \\
2007 & 1.09 & 1.09 & 0.088 & $(0.92,1.31)$ & $(0.29,1.88)$ \\
CMass & & & & & \\
1999 & 914 & 925 & 13.7 & $(897,953)$ & $(777,1073)$ \\
2000 & 953 & 947 & 18.5 & $(910,985)$ & $(797,1098)$ \\
2001 & 911 & 972 & 26.3 & $(918,1026)$ & $(817,1127)$ \\
2002 & 998 & 890 & 16.7 & $(855,924)$ & $(740,1039)$ \\
2003 & 940 & 898 & 14.8 & $(868,929)$ & $(750,1047)$ \\
2004 & 796 & 870 & 22.5 & $(824,916)$ & $(717,1022)$ \\
2005 & 992 & 901 & 14.3 & $(872,931)$ & $(753,1049)$ \\
2006 & 976 & 938 & 16.0 & $(905,971)$ & $(789,1087)$ \\
2007 & 1020 & 942 & 16.9 & $(907,984)$ & $(792,1091)$ \\
& & & & & \\
\hline
\end{tabular}

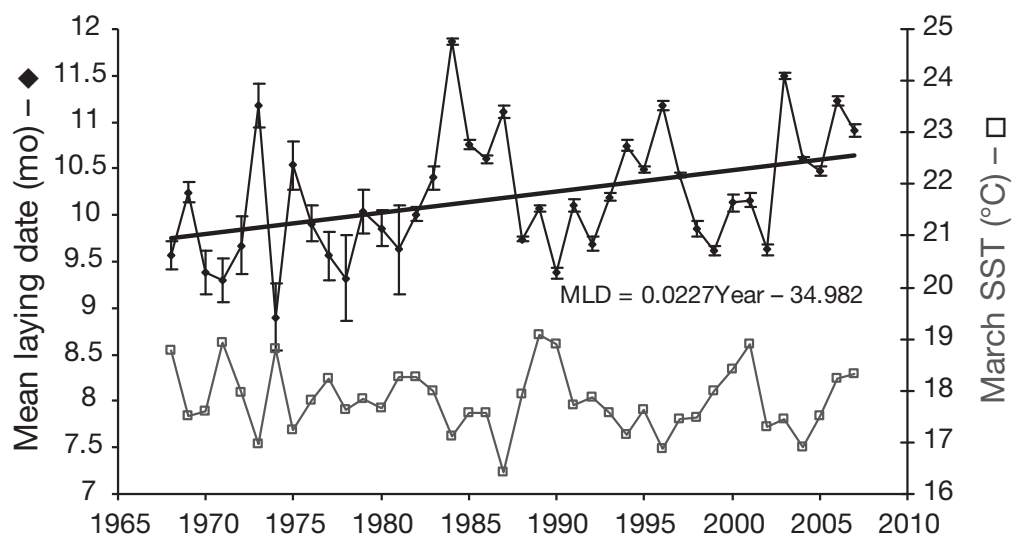

Fig. 4. Eudyptula minor. Temporal trend in annual timing of mean laying date of little penguins on Phillip Island (with associated standard errors). Also shown are the March sea surface temperature (SST) values for the SST sub-region of Fig. 1

\section{DISCUSSION}

The timing of egg-laying of little penguins on Phillip Island was significantly and negatively correlated with SST in southeastern Australia at some times of the year. Warmer temperatures in late summer and autumn corresponded to earlier nesting. To a lesser extent, CPP and CMass at fledging were positively correlated with SST. In years with warmer temperatures from late summer to early winter, there tended to be higher numbers of chicks and an increase in CMass.

Variation in SST has been reported to correlate with the timing and productivity of breeding in little penguins, both negatively and positively (Wooller et al. 1991, Mickelson et al. 1992, Perriman et al. 2000, Chambers 2004a,b). For example, Leeuwin Current strength affected the timing of breeding of little penguins on Penguin Island in Western Australia (Wooller et al. 1991, Wienecke et al. 1995). In contrast to our study, in years when the Leeuwin Current was strong, and consequently water temperatures were higher, little penguins in Western Australia laid much later (Wooller et al. 1991). Also in contrast to our study, Mickelson et al. (1992) found that a decrease in SST in July-August was associated with earlier egg laying, while we have shown that this is more closely associated with warm SST in March. The reason for the difference between Mickelson et al. (1992) and our study could be related to their significantly shorter time series, smaller sample sizes, fewer breeding sites and limited SST regions. However, their correlations were significant during a similar time of the year and it is possible that a computational error was responsible for the difference in sign. In New Zealand, the El NiñoSouthern Oscillation influences ocean temperatures and with cooler waters in the Pacific Ocean, the breeding of little penguin is delayed and there are fewer double breeders (Perriman et al. 2000). These regional differences in the reproductive response of little penguins to SST suggests that there is not a direct relationship with temperature and metabolic rates; rather a more complex ecological process is likely to be involved.

Our results are more consistent with an earlier study on the breeding of little penguins in southern Australia by Chambers (2004a) using a coarser spatial-resolution SST and air temperature. She found that egg laying coincided with times when local SST was rising. Warmer minimum monthly air temperature close to Phillip Island during the autumn prior to breeding corresponded to earlier breeding, as 
did warmer local SST in the summer and autumn prior to breeding. These relationships were used to predict breeding success in little penguins (Chambers 2004b) but the forecast scheme differed from that presented here in that it produced categorical rather than empirical predictions.

\section{Predictions}

SST data predicted the penguin breeding variables reasonably well. As far as the predictions go, the models developed are statistically optimal. As SST values over the entire southern Australian region were highly correlated, this indicates that SST extending across all 4 water masses around the southeastern Australian coast is associated with the timing and success of breeding of little penguins on Phillip Island. Timing of breeding in other seabirds, such as Cassin's auklet Ptychoramphus aleuticus (Ainley \& Boekelheide 1990), has also been predicted using SST prior to commencement of breeding.

\section{Accuracy of models}

The predictive equations performed relatively well on the historical data, as might be expected since these data were used to develop the model, but less well in predictive mode on post-1998 data, which were not included in the model development. The confidence and prediction intervals for MLD were much tighter than those for CPP and CMass. For CPP and CMass, the prediction intervals were quite wide and therefore almost all of the observed and predicted values fell within these intervals. Over the model testing period, 1999 to 2007, the mean laying date was relatively well predicted, with the following exceptions: 2003, 2006 and 2007. In 2003, there was a tentative start to breeding in September, when only few birds laid eggs, but most birds did not breed until November. The MLDs in 2006 and 2007 were also later than expected. With further investigation, these exceptional years may provide an indication of the ecological processes that drive these relationships.

\section{Potential mechanisms for the effects of SST on breeding}

A number of studies demonstrate a negative connection between SST and the timing and success of breeding in seabirds (e.g. Boersma 1978, Guinet et al. 1998, Smithers et al. 2003, Congdon et al. 2007), presumably due to the influence of SST or upwelling on the condi- tion of the food web (Ainley \& Boekelheide 1990). However, in the $31 \mathrm{yr}$ of this study, the strongest correlations of breeding parameters with SST were positive (an earlier MLD being a positive outcome) and occurred 6 to 7 mo before breeding.

Variations in SST have been associated with recruitment, productivity and distribution of fish and other marine vertebrates in southern Australian waters (Harris et al. 1988). For example, more southern bluefin tuna Thunnus maccoyii were present off Maria Island in years of low SST, whereas populations of spiny rock lobster Jasus edwardsii were higher in years of higher SST at the same location (Harris et al. 1988). In New Zealand, increased catches of red cod Pseudophycis bachus, barracuda Thyristes atun and blue warehou Seriolella brama occurred during the 1982 to $1983 \mathrm{El}$ Niño, corresponding to a period of cooler SST in New Zealand (Basher 1998). In years of warmer ocean temperatures, larval and juvenile survival of gemfish and snapper was higher and deeper water species, such as hoki Macruronus novaezealandiae and silver warehou Seriolella punctata, moved to the shallower coastal waters of the east coast of northern New Zealand (Basher 1998). Movement of fish and altered timing of peak productivity of spawning and juvenile prey species are also expected to occur in southern temperate regions of Australia as a result of changes in sea surface temperature (Congdon et al. 2007).

In this study, warm water that occurred up to 6 mo prior to the onset of the breeding season was associated with an earlier-than-average start to breeding and improved the breeding success of little penguins on Phillip Island. Although there is considerable interannual variability, it appears that waters to the east and west of Bass Strait are influenced by mixing of continental shelf waters, which bring higher concentrations of nutrients in winter (Gibbs 1992). The concentration of nitrates in Bass Strait water declines seasonally from a peak in July/August to low levels in December (Norman 1992). Penguin breeding may be affected by changes in marine productivity associated with SST and driven by oceanographic processes (Middleton \& Cirano 2002).

At the time of breeding, SST appeared to have weaker association with the success of breeding. There are at least 2 possible explanations for the association between warmer water and more successful breeding that warrant further investigation: (1) a longer breeding season and (2) greater availability and quality of food.

\section{Longer breeding season}

Our results have shown that CPP increases during years when SST is warmer and that this is related to 
early egg laying, which increases the length of the breeding season. A longer breeding season allows more time for replacement clutches and second clutches (Reilly \& Cullen 1981), since there is little annual variation in the date when egg laying ceases.

\section{Availability and quality of food}

Breeding success in little penguins has been linked to adult weight and the availability and quality of food may determine the onset of laying (Cullen et al. 1992, Robinson et al. 2005). Alternatively, the warmer water earlier in the year (i.e. March to April) may improve breeding success by resulting in more prey (or higher quality food) being available closer to the breeding colony. Better nutrition for chicks during warm years would increase chick masses, which increases both fledging success and post-fledging survival rates (Reilly \& Cullen 1981, Dann 1988, Dann \& Cullen 1990, Chiaradia \& Nisbet 2006).

Little penguins eat fish and squid, but their diet consists mostly of small clupeiform fish, particularly anchovy Engraulis australis and pilchard Sardinops sagax, that are less than $10 \mathrm{~cm}$ long and less than $2 \mathrm{yr}$ old (Cullen et al. 1992, Chiaradia et al. 2004). When feeding their chicks, penguins usually forage within $30 \mathrm{~km}$ of Phillip Island but may travel greater distances in some years when food is apparently less abundant (Weavers 1992, Collins et al. 1999, Dann \& Norman 2006). SST could influence the local abundance of these small pelagic fishes in several ways. Interannual differences in temperature may directly or indirectly effect the distribution, recruitment, growth and mortality of prey species in the 6 mo leading up to and during breeding (Harris et al. 1988, Basher 1998). Fluctuations in anchovy and pilchard stocks have also been attributed to changes in water temperature (Hoedt et al. 1996). So it is possible that similar ecological mechanisms are forcing the breeding dynamics of the little penguin colony at Phillip Island.

\section{Implications for predicting climate change effects}

More information is needed on the potential impact of climate change on the future trends in the productivity of Australian marine ecosystems. Climate change projections are for warming of waters in the region and a strengthening of the EAC (IPCC 2007), bringing warmer waters further south. This is expected to have flow-on effects on marine biota, productivity and the local abundance of the prey for little penguins. Longterm biological data sets, such as those recorded at Phillip Island, are uncommon and of high scientific value for anticipating climate change impacts. The models presented here, based on the water temperatures experienced over the last $30 \mathrm{yr}$, predict that increased SST, at least in the immediate future, is likely to lead to a reversal of the trend towards later breeding; the models also suggest improved growth of the colony of little penguins on Phillip Island in Victoria, provided no currently unknown detrimental temperature-dependent marine productivity thresholds are breached or that temperature changes are not too rapid (Irons et al 2008).

Although there were no significant trends in SST during the January to June prior to the breeding season, the onset of breeding of little penguins on Phillip Island became later over time (Fig. 4), but with considerable year-to-year variability in MLD. Previous studies have shown that the cessation of breeding each year varies little with time (Reilly \& Cullen 1981), which could be related to photoperiod, as has been observed in other seabird species (Ainley \& Boekelheide 1990). The environmental factors and stimulus for the onset of breeding in little penguins are still unknown, but our modelling demonstrates that breeding timing and success can be predicted by water temperatures in the western Bass Strait region during March.

Validation of the predictions and improvement of the models are warranted to account for the lower performance of the models in predicting the mean laying date in 2003, 2006 and 2007. It is also important to determine the ecological mechanisms driving these relationships in Victoria and in other locations, given the opposite effect of SST on reproduction of little penguins in Western Australia and differences in the breeding season of little penguin colonies in South Australia.

Acknowledgements. It is a pleasure to acknowledge the assistance provided by all involved directly and indirectly with the research program at the Phillip Island Nature Park and the Penguin Study Group. Additional information was provided by various staff from the Bureau of Meteorology. H. Beggs, A. Chiaradia, P. Sandery and 3 anonymous reviewers provided helpful advice on earlier drafts of this article.

\section{LITERATURE CITED}

Ainley DG, Boekelheide RJ (1990) Seabirds of the Farallon Islands. Stanford University Press, Stanford, CA

Ainley DG, Carter HR, Anderson DW, Briggs KT and others (1988) Effects of the 1982-83 El Niño-Southern Oscillation on Pacific Ocean bird populations. Acta XIX Congressus Internationalis Ornithologici II:1747-1758

> Arnould JPY, Dann P, Cullen JM (2004) Determining the sex of little penguins (Eudyptula minor) in northern Bass Strait using morphometric measurements. Emu 104: 261-265 
Barbraud C, Weimerskirch H (2001) Emperor penguins and climate change. Nature 411:183-185

Basher R, (1998) The 1997/98 El Niño event: impacts, responses and outlook for New Zealand. New Zealand Ministry of Research. Sci Technol Rep 73

Boersma PD (1978) Breeding patterns of Galapagos penguins as an indicator of oceanographic conditions. Science 200: 1481-1483

Boersma PD (1987) El Niño behind penguin deaths? Nature 327:96

Carscadden J, Nakashima BS, Frank KT (1997) Effects of fish length and temperature on the timing of peak spawning in capelin (Mallotus villosus). Can J Fish Aquat Sci 54: 781-787

Chambers LE (2004a) Delayed breeding in little penguinsevidence of climate change? Aust Meteorol Mag 53:13-19

Chambers LE (2004b) The impact of climate on little penguin breeding success. BMRC Research Report No. 100, Bureau of Meteorology, Melbourne

Chiaradia A, Nisbet ICT (2006) Plasticity in parental provisioning and chick growth in little penguins Eudyptula minor in years of high and low breeding success. Ardea 94:257-270

Chiaradia A, Dann P, Cullen M (2004) Dietary diversity and breeding success of little penguins. NZ J Zool 31:116-117

Collins M, Cullen JM, Dann P (1999) Seasonal and annual foraging movements of little penguins from Phillip Island, Victoria. Wildl Res 26:705-721

Congdon BC, Erwin CA, Peck DR, Baker GB, Double MC, O'Neill P (2007) Vulnerability of seabirds on the Great Barrier Reef to climate change. In: Johnson JE, Marshall PA (eds) Climate change and the Great Barrier Reef. Great Barrier Reef Marine Park Authority and the Australian Greenhouse Office, Townsville, p 427-463

Crawford RJM, Jahncke J (1999) Comparison of trends in abundance of guano-producing seabirds in Peru and southern Africa. S Afr J Mar Sci 21:145-156

Cullen JM, Montague TL, Hull C (1992) Food of little penguins Eudyptula minor in Victoria: comparison of three localities between 1985 and 1988. Emu 91:318-341

Cunningham DM, Moors PJ (1994) The decline of rockhopper penguins Eudyptes chrysocome at Campbell Island, Southern Ocean and the influence of rising sea temperatures. Emu 94:27-36

Dann P (1988) An experimental manipulation of clutch size in the little penguin Eudyptula minor. Emu 88:101-103

Dann P, Cullen JM (1990) Survival, patterns of reproduction and lifetime reproductive output in the little blue penguins (Eudyptula minor) on Phillip Island, Victoria, Australia. In: Davis LS, Darby JT (eds) Penguin biology. Academic Press, San Diego, CA, p 63-84

Dann P, Norman FI (2006) Population regulation in little penguins Eudyptula minor: the role of intraspecific competition for nesting sites and food during breeding. Emu 106:289-296

Dann P, Cullen JM, Jessop R (1995) Cost of reproduction in little penguins. In: Dann P, Norman I, Reilly P (eds) The penguins. Surrey Beatty \& Sons, Sydney, p 39-55

Dann P, Norman FI, Cullen JM, Neira FJ, Chiaradia A (2000) Mortality and breeding failure of little penguins, Eudyptula minor, in Victoria, 1995-96, following a widespread mortality of pilchard, Sardinops sagax. Mar Freshw Res 51:355-362

Gibbs CF (1992) Oceanography of Bass Strait: implications for the food supply of little penguins Eudyptula minor. Emu 91:395-401

Glantz MH (2001) Currents of change: impacts of El Niño and
La Niña on climate and society, 2nd edn. Cambridge University Press, New York

Guinet C, Chastel O, Koudil M, Durbec JP, Jouventin P (1998) Effects of warm sea-surface temperature anomalies on the blue petrel at the Kerguelen Islands. Proc R Soc Lond B Biol Sci 265:1001-1006

> Harris G, Davies P, Nunez M, Meyers G (1988) Interannual variability in climate and fisheries in Tasmania. Nature 333:754-757

Hodder J, Graybill MR (1985) Reproduction and survival of seabirds in Oregon during the 1982-1983 El Niño. Condor 87:535-541

Hoedt FE, Jones K, Jackson G, Dimmlich WF (1996) Studies on the relationship between sea surface temperature and the distribution of pilchards (Sardinops sagax neopilchardus Steindachner) in gulf and shelf waters of South Australia. In: Aung TH (ed) Proceedings of the Ocean and Atmosphere Pacific International Conference. National Tidal Facility, The Flinders University of South Australia, Adelaide, p 103-108

Inchausti P, Guinet C, Koudil M, Durbec JP and others (2003) Inter-annual variability in the breeding performance of seabirds in relation to oceanographic anomalies that affect the Crozet and the Kerguelen sectors of the Southern Ocean. J Avian Biol 34:170-176

IPCC (2007) Climate change impacts, adaptation and vulnerability. In: Parry ML, Canziani OF, Palutikof JP, van der Linden PJ, Hanson CE (eds) Contribution of Working Group II to the Fourth Assessment Report of the Intergovernmental Panel on Climate Change. Cambridge University Press, Cambridge, p 507-540

Irons DB, Anker-Nilssen T, Gaston AJ, Byrd GV and others (2008) Fluctuations in circumpolar seabird populations linked to climate oscillations. Glob Change Biol 14:1455-1463

Kemp A, Dann P (2001) Egg size, incubation periods and hatching success of little penguins Eudyptula minor. Emu 101:249-253

La Cock GD (1986) The Southern Oscillation, environmental anomalies, and mortality of two southern African seabirds. Clim Change 8:173-184

Mickelson MJ, Dann P, Cullen JM (1992) Sea temperature in Bass Strait and breeding success of the little penguin Eudyptula minor at Phillip Island, south-eastern Australia. Emu 91:355-368

Middleton JF, Cirano M (2002) A northern boundary current along Australia's southern shelves: the Flinders Current. J Geophys Res C 107:3129. doi:10.1029/2000JC000701

Montevecchi WA, Myers RA (1996) Dietary changes of seabirds reflect shifts in pelagic food webs. Sarsia 80: $313-322$

Norman FI (1992) Counts of little penguins Eudyptula minor in Port Phillip Bay and off southern Phillip Island, Victoria, 1986-1988. Emu 91:287-301

Parker DE, Folland CK, Bevan AC, Ward MN, Jackson M, Maskerll K (1995) Marine surface data for analysis of climatic fluctuations on interannual-to-century time scales. In: Climate Research Committee (ed) Natural climate variability on decade-to-century time scales. National Academic Press, Washington, DC, p 241-252

Perriman L, Houston D, Steen H, Johannesen E (2000) Climate fluctuation effects on breeding of blue penguins (Eudyptula minor). NZ J Zool 27:261-267

> Regehr HM, Montevecchi WA (1997) Interactive effects of food shortage and predation on breeding failure of blacklegged kittiwakes: indirect effects of fisheries activities and implications for indicator species. Mar Ecol Prog Ser 155:249-260 
Reilly PN, Cullen JM (1981) The little penguin Eudyptula minor in Victoria. II: Breeding. Emu 81:1-19

Reynolds RW, Smith TM (1994) Improved global sea surface temperature analysis using optimum interpolation. J Clim 7:929-948

Robinson S, Chiaradia A, Hindell MA (2005) The effect of body condition on the timing and success of breeding in little penguins Eudyptula minor. Ibis 147:483-489

Smithers BV, Peck DR, Krockerberger AK, Congdon BC (2003) Elevated sea-surface temperature, reduced provisioning and reproductive failure of wedge-tailed shearwaters (Puffinus pacificus) in the southern Great Barrier Reef, Australia. Mar Freshw Res 54:973-977

Tabachnick BG, Fidell LS (1996) Using multivariate statistics, 3rd edn. Harper Collins College Publishers, New York

Editorial responsibility: John Piatt,

Anchorage, Alaska, USA
Velarde E, Ezcurra E, Cisneros-Mata MA, Lavin MF (2004) Seabird ecology, El Niño anomalies, and prediction of sardine fisheries in the Gulf of California. Ecol Appl 14: $607-615$

Weavers BW (1992) Seasonal foraging ranges and travels at sea of little penguins Eudyptula minor, determined from radio tracking. Emu 91:302-317

Wienecke BC, Wooller RD, Klomp NI (1995) The ecology and management of little penguins on Penguin Island, Western Australia. In: Dann P, Norman I, Reilly P (eds) The penguins. Surrey Beatty \& Sons, Sydney, p 440-467

Wooller RD, Dunlop JN, Klomp CE, Meathrel CE, Wienecke BC (1991) Seabird abundance, distribution and breeding patterns in relation to the Leeuwin Current. J R Soc West Aust 74:1-4

Submitted: March 17, 2008; Accepted: December 5, 2008 Proofs received from author(s): March 6, 2009 